\title{
Intracranial application of near-infrared light in a hemi-parkinsonian rat model: the impact on behavior and cell survival
}

\author{
Florian Reinhart, BSc, ${ }^{1}$ Nabil El Massri, BSc, ${ }^{2}$ Claude Chabrol, BEng, ${ }^{1}$ Celine Cretallaz, PhD, ${ }^{1}$ \\ Daniel M. Johnstone, PhD, ${ }^{3}$ Napoleon Torres, MD, PhD, ${ }^{1}$ Fannie Darlot, PhD, ${ }^{1}$ \\ Thomas Costecalde, PhD, ${ }^{1}$ Jonathan Stone, PhD, DSc, ${ }^{3}$ John Mitrofanis, $\mathrm{PhD},{ }^{2}$ \\ Alim-Louis Benabid, MD, PhD, ${ }^{1}$ and Cécile Moro, $\mathrm{PhD}^{1}$
}

${ }^{1}$ CEA, Leti, and Clinatec Departments, University Grenoble Alpes, Minatec Campus, Grenoble, France; and Departments of ${ }^{2}$ Anatomy and ${ }^{3}$ Physiology, University of Sydney, New South Wales, Australia

OBJECTIVE The authors of this study used a newly developed intracranial optical fiber device to deliver near-infrared light (NIr) to the midbrain of 6-hydroxydopamine (6-OHDA)-lesioned rats, a model of Parkinson's disease. The authors explored whether NIr had any impact on apomorphine-induced turning behavior and whether it was neuroprotective.

METHODS Two NIr powers ( $333 \mathrm{nW}$ and $0.16 \mathrm{~mW}$ ), modes of delivery (pulse and continuous), and total doses (634 mJ and $304 \mathrm{~J}$ ) were tested, together with the feasibility of a midbrain implant site, one considered for later use in primates. Following a striatal 6-OHDA injection, the NIr optical fiber device was implanted surgically into the midline midbrain area of Wistar rats. Animals were tested for apomorphine-induced rotations, and then, 23 days later, their brains were aldehyde fixed for routine immunohistochemical analysis.

RESULTS The results showed that there was no evidence of tissue toxicity by NIr in the midbrain. After 6-OHDA lesion, regardless of mode of delivery or total dose, NIr reduced apomorphine-induced rotations at the stronger, but not at the weaker, power. The authors found that neuroprotection, as assessed by tyrosine hydroxylase expression in midbrain dopaminergic cells, could account for some, but not all, of the observed behavioral improvements; the groups that were associated with fewer rotations did not all necessarily have a greater number of surviving cells. There may have been other "symptomatic" elements contributing to behavioral improvements in these rats.

CONCLUSIONS In summary, when delivered at the appropriate power, delivery mode, and dosage, NIr treatment provided both improved behavior and neuroprotection in 6-OHDA-lesioned rats.

http://thejns.org/doi/abs/10.3171/2015.5.JNS15735

KEY WORDS functional neurosurgery; neuroprotection; Parkinson's disease; photobiomodulation; substantia nigra; 6-hydroxydopamine

$\mathrm{P}$ ARKINSON's disease is a progressive disorder with distinct cardinal signs of resting tremor, lead-pipe rigidity, akinesia, bradykinesia, or all of these. ${ }^{2,24}$ The current treatment options of drug therapy and surgery treat the motor signs of the disease very well, at least initially, but they do not stop the progression of the disease. The dopa- minergic cells in the substantia nigra pars compacta $(\mathrm{SNc})$ continue to die throughout the treatment period. . $^{3,3,35,49}$ In essence, these treatments do not offer neuroprotection.

Many recent studies, from the culture dish to various animal models, provide promising evidence that near-infrared light (NIr) treatment is an effective neuroprotective

ABBREVIATIONS ATP = adenosine-5'-triphosphate; $\mathrm{CPu}=$ caudate-putamen complex; GFAP = glial fibrillary acidic protein; IBA1 = ionized calcium binding adaptor molecule 1; LED = light-emitting diode; MPTP = 1-methyl-4-phenyl-1,2,3,6-tetrahydropyridine; NIr = near-infrared light; NIrC = continuous NIr at weaker power; NIrC+ = continuous NIr at stronger power; NIrP = pulse NIr; PBS = phosphate-buffered saline; RHS = right-hand side; SNc = substantia nigra pars compacta; $\mathrm{SNr}=$ substantia nigra pars reticulata; $\mathrm{TH}=$ tyrosine hydroxylase; $\mathrm{VTA}=$ ventral tegmental area; $6-\mathrm{OHDA}=6$-hydroxydopamine.

SUBMITTED April 1, 2015. ACCEPTED May 21, 2015.

INCLUDE WHEN CITING Published online November 27, 2015; DOI: 10.3171/2015.5.JNS15735. 
agent..$^{8,9,27,39}$ NIr treatment has been shown to increase cell survival among dopaminergic cells after various types of parkinsonian insult, for example rotenone, ${ }^{29,55}$ 1-methyl4-phenyl-1,2,3,6-tetrahydropyridine (MPTP), ${ }^{12,28,32,33,40,45,52}$ and the K3691 transgenic mutation. ${ }^{42}$ The precise mechanism involved is not clear, but NIr is believed to repair mitochondrial damage and increase adenosine-5'-triphosphate (ATP) production, as well as decrease oxidative stress and activate various transcription factors. ${ }^{7,15,16,47}$ In addition to this structural evidence of neuroprotection, NIr treatment has been reported to improve locomotor activity in MPTP-treated mice. ${ }^{33,45,54}$

The neuroprotective effects of NIr have been reported in cases where there have been no (e.g., culture dish) or few tissue barriers (e.g., retina or small mouse brain). In fact, the farthest distance that NIr has been traced from the source is approximately $30 \mathrm{~mm}$, a distance well short of the $80-100 \mathrm{~mm}$ required to reach the $\mathrm{SNc}$ from the surface of the brain in humans. ${ }^{27}$ This makes NIr directed transcranially unlikely to be useful for treating midbrain lesions in humans. To overcome this, we have been developing an optical fiber device that can be implanted accurately within the brain, to deliver NIr with minimal attenuation to regions near the SNc. Our recent results in MPTP-treated mice show that intracranially applied NIr does not cause toxic damage to surrounding brain tissue when applied in the region of the lateral ventricle, and that when applied in this fashion and location, it is neuroprotective to dopaminergic SNc cells. ${ }^{32}$

In this study, we used the intracranial optical fiber device to deliver NIr to the SNc in another model of Parkinson's disease, the 6-hydroxydopamine (6-OHDA) hemiparkinsonian rat. Because there is no ideal animal model of Parkinson's disease, exploring the neuroprotective and behavioral effects of NIr in a number of models strengthens the case for translation to humans. We have explored 2 main issues in this study. First, we analyzed whether the midbrain is a feasible implant site. Our previous study in mice, for species-specific technical reasons, used the lateral ventricle as a target site, ${ }^{32}$ but for our planned monkey and human work, we will target a region closer to the $\mathrm{SNc}$, namely the midline midbrain at a point midway between the left and right SNc. Second, we analyzed whether NIr had any impact on apomorphine-induced rotational behavior or was neuroprotective, or both, in 6-OHDA-lesioned rats. We tested the impact of different NIr applications, using 2 powers (333 nW and 0.16 $\mathrm{mW}$ ), modes of delivery (pulse and continuous), and total doses (634 $\mathrm{mJ}$ and $304 \mathrm{~J}$ ). We have evidence regarding some of these issues in the MPTP-treated mouse model using the intracranial device, ${ }^{32}$ but no evidence is available in the 6-OHDA-lesioned rat model or on behavioral outcomes. Overall, our findings will indicate whether NIr improves behavior and offers neuroprotection in another model of the disease, as well as whether the midline of the midbrain is a feasible optical fiber implant site.

\section{Methods \\ Animals}

Male Wistar rats (approximately 8 weeks old; $n=61$ ) were used for these experiments. Animals were housed on a 12-hr light/dark cycle with unlimited access to food and water. All experiments were approved by the Animal Ethics Committee COMETH (Grenoble) and by the French Ministry for Research.

\section{Experimental Design}

We set up 5 experimental groups (Fig. 1). All groups received intrastriatal injections of either 6-OHDA or saline, combined with light-emitting diode (LED)-optical fiber implants delivering NIr, or not. The different groups were saline (saline injections, no NIr; $\mathrm{n}=8$ ), 6-OHDA (6-OHDA injections, no NIr; $n=15$ ), and 6-OHDA-NIr (6-OHDA injections, with NIr; $n=38$ ) groups. There were 3 6-OHDA-NIr groups, each of which received different doses of NIr during the course of the survival period. These were the 6-OHDA-NIrP (NIr delivered in pulses at $0.16 \mathrm{~mW}$ power; $\mathrm{n}=16), 6-\mathrm{OHDA}-\mathrm{NIrC}+(\mathrm{NIr}$ delivered continuously at $0.16 \mathrm{~mW}$ power; $\mathrm{n}=13$ ), and 6-OHDANIrC (NIr delivered continuously but at $333 \mathrm{nW}$ power; $\mathrm{n}=9$ ) groups. A saline group exposed to NIr was not included, because we have previously published that NIr has no impact on the survival and function of cells in normal brains. ${ }^{12,28,32,33,40,45,52}$ Given the consistency of these previous results, and the complexity of our surgical protocol, we believed that the extra control group was redundant.

Our experimental paradigm of simultaneous administration of parkinsonian insult and therapeutic application was similar to that of previous studies of animal models of Parkinson's disease. ${ }^{12,28,32,33,40,41,45,52,53}$ This paradigm is unlike the clinical reality in which there is cell loss prior to therapeutic intervention. However, in our experimental study, we hoped to determine the maximum effect of any NIr neuroprotection by the LED-optical fiber implant.

\section{6-OHDA Injections}

Following protocols used in many previous studies, ${ }^{13,18,31,41}$ rats were anesthetized after an intraperitoneal injection of ketamine $(100 \mathrm{mg} / \mathrm{kg}$; Imalgène $1000 ; \mathrm{Me}$ rial) and xylazine (10 mg/kg; Rompun; Bayer Animal Health), and they had 6-OHDA $(7.5 \mu \mathrm{g} / \mu \mathrm{l}$ saline with addition of $0.2 \%$ ascorbic acid; approximately $4 \mu \mathrm{l}$ injected over 8 minutes) or saline (plus $0.2 \%$ ascorbic acid) injected stereotactically into the caudate-putamen complex $(\mathrm{CPu}$; coordinates: anteroposterior $+1 \mathrm{~mm}$, lateral +3 $\mathrm{mm}$, dorsal-ventral $-6.3 \mathrm{~mm}$ to skull) ${ }^{39}$ of the right-hand side (RHS). We injected the $\mathrm{CPu}$, rather than the medial forebrain bundle, because we wanted a smaller lesion in the SNc (20\%-30\%); medial forebrain bundle injections are known to generate larger lesions and massive SNc cell death $(>70 \%)$, a situation not ideal for neuroprotection studies. ${ }^{13,18,31,41}$

\section{Optical Fiber NIr Implants}

After the 6-OHDA injection, we implanted the LEDoptical fiber device, as described previously in mice. ${ }^{32}$ Briefly, a small 670-nm LED (SMT 670; Epitex) was attached to an optical fiber (FT300EMT; Thorlabs) with a tip diameter of $300 \mu \mathrm{m}$ (Fig. 2A). The step index optical fiber was plastic coated, as to limit leakage of NIr along the 


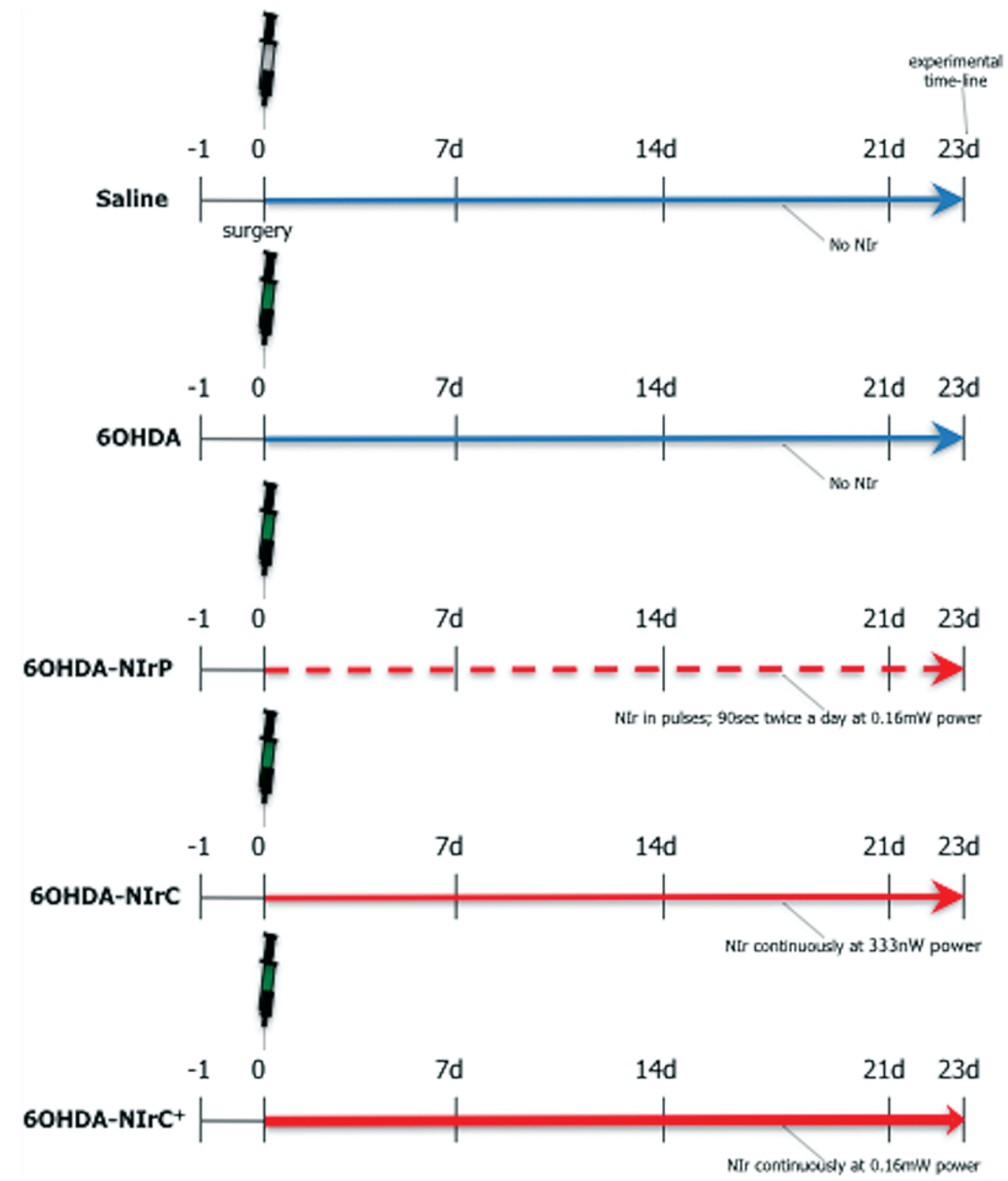

FIG. 1. Outline of the experimental design of this study. Surgery on rats, namely 6-OHDA or saline injection and implantation of optical fiber, was performed on Day 0. Animals were allowed to survive for 23 days thereafter. In the 6-OHDA-NIrP group, NIr was applied for 90 seconds twice a day, while in the 6-OHDA-NIrC groups, NIr was applied continuously during the survival period; in the 6-OHDA-NIrC+ group, NIr was emitted at a higher power than in the other NIr groups. Rats were tested for apomorphineinduced turning behavior on Day -1 (day before surgery) as well as Day 7, Day 14, and Day 21 after surgery. Figure is available in color online only.

length of the fiber and focus to the tip. The LED was attached with electrical cables that would be connected subsequently to a current regulator circuit and battery source (Fig. 2A). All LED-optical fibers were tested for power output using a calibrated light sensor (Optical power meter, Anritsu ML9002A). We found that the LED emitted no heat and was satisfactory for use over longer periods. The optical fiber was implanted stereotactically into a region near the SNc, incorporating the red nucleus and ventral tegmental area (VTA), toward the midline (Fig. 2B; coordinates to bregma: anteroposterior $-5.6 \mathrm{~mm}$, lateral
$+2.9 \mathrm{~mm}$, dorsal-ventral $-8.5 \mathrm{~mm}$ to skull, at an angle of $\left.20^{\circ}\right) .{ }^{39} \mathrm{We}$ chose this site because it is close to the SNc of both sides. After implantation, biological cement was used to attach the device to the cranium, and the proximal ends of the battery cables were attached to the device, while the distal ends were attached to a battery source placed on top of the rat cage (Fig. 2C-E). ${ }^{32}$ Immediately following the surgery, rats in the 6-OHDA-NIrP group had 0.16 $\mathrm{mW}$ power (the same power as used previously for neuroprotection in MPTP-treated mice) $)^{32}$ delivered in pulses, twice a day for $90 \mathrm{sec}$ (approximately 6 hours apart) 

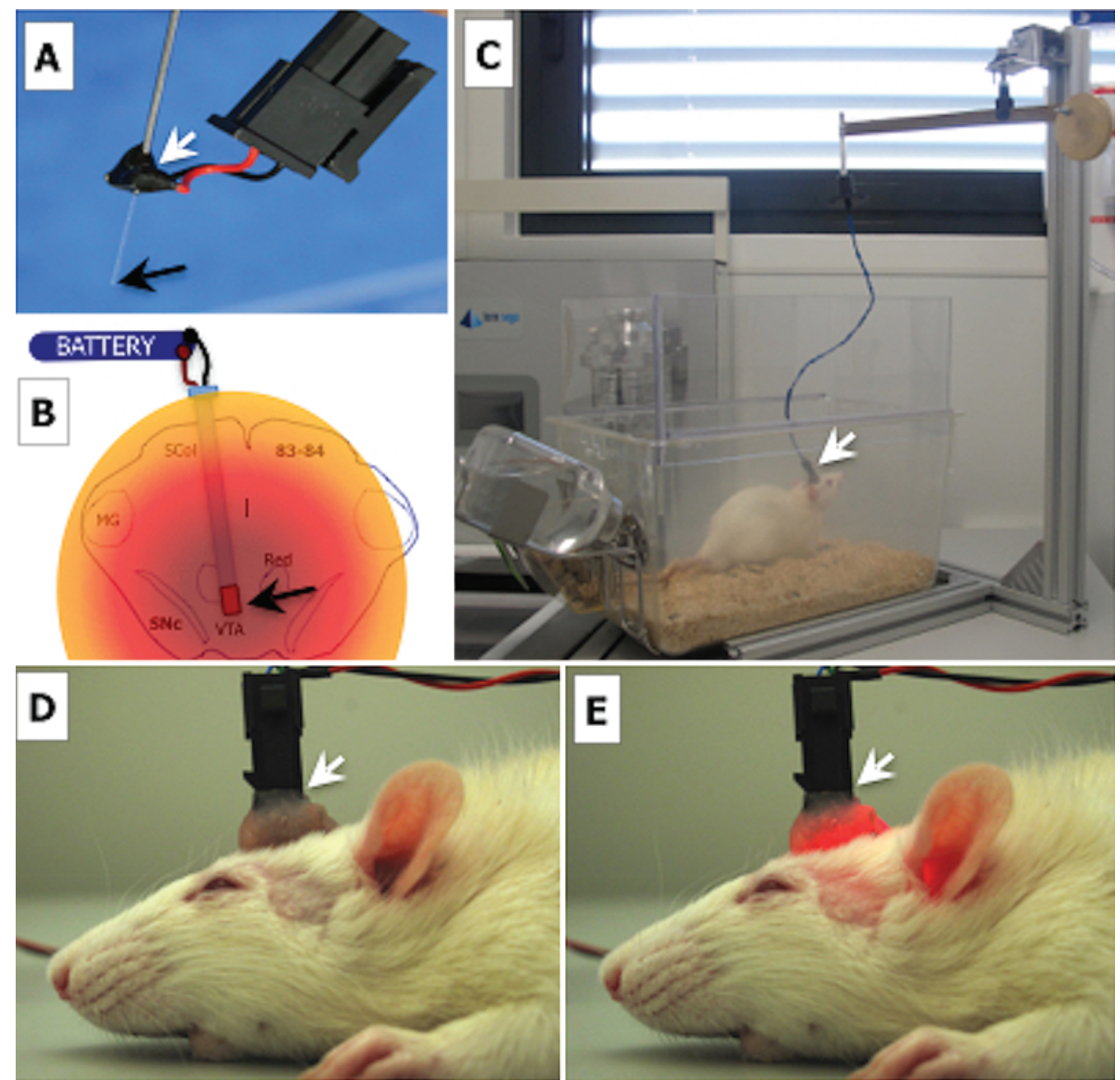

FIG. 2. A: Image of the LED-optical fiber device; white arrow indicates the LED, while the black arrow indicates the optical fiber (these arrows indicate corresponding structures in B-E). B: Schematic diagram of optical fiber located within our target region near the SNc. C: Image of rat, soon after surgery, with cable attached to battery source on top of the cage. This setup allowed the rat to move freely around the cage, eating and drinking at will. D and E: Images of a rat soon after surgery with the implanted LED-optical fiber device turned off (D) and on (E). This animal was still anesthetized following surgery. Note that the NIr was visible through the biological cement surrounding the device, the skin, and auricles, and although not obvious in this image, the eyes. The black arrows indicate the tip of the optical fiber, while the white arrows indicate the LED device. Red = red nucleus. Figure is available in color online only.

over the 23-day survival period, resulting in a total dose of $634 \mathrm{~mJ}$ (Table 1). Rats in the 6-OHDA-NIrC+ group also had $0.16 \mathrm{~mW}$ power, but this was delivered continuously over the 23-day survival period, resulting in a much higher total dose of $304 \mathrm{~J}$. These 2 groups thus allowed us to compare the effectiveness of $2 \mathrm{NIr}$ doses delivered at the same power. Finally, the rats in the 6-OHDA-NIrC group had a weaker $333 \mathrm{nW}$ power delivered continuously over the survival period, resulting in the same total dose as the 6-OHDA-NIrP group of $634 \mathrm{~mJ}$. Hence, the 6-OHDANIrP and 6-OHDA-NIrC groups allowed us to compare the effectiveness of the same dose, but delivered by 2 different NIr powers (Table 1).

For several reasons, we are confident that any neuroprotective or behavioral improvement after NIr treatment would not be related to a direct deactivation or degradation of the toxin by NIr. First, NIr offers beneficial effects to diseased or damaged neurons in a broad range of neurological conditions and animal models of disease. For example, NIr is neuroprotective after 1) insult by a number of different toxins (e.g., MPTP, rotenone, methanol) ${ }^{11,29,55}$ 2) traumatic brain injury, ${ }^{37,44} 3$ ) stroke, ${ }^{36} 4$ ) macular degeneration, ${ }^{21}$ and 5) transgenic mutation in mouse models

TABLE 1. The modes of NIr delivery, power, and total doses used in the different groups of this study

\begin{tabular}{llll}
\hline \multicolumn{1}{c}{ Group } & Mode of NIr Delivery & Power & Total Dose \\
\hline Saline & None & None & None \\
\hline 6-OHDA & None & None & None \\
\hline 6-OHDA-NIrP & Pulse, 90 sec twice a day & $0.16 \mathrm{~mW}$ & $634 \mathrm{~mJ}$ \\
\hline 6-OHDA-NIrC & Continuous & $333 \mathrm{nW}$ & $634 \mathrm{~mJ}$ \\
\hline 6-OHDA-NIrC+ & Continuous & $0.16 \mathrm{~mW}$ & $304 \mathrm{~J}$ \\
\hline
\end{tabular}


of multiple sclerosis,$^{34}$ Alzheimer's disease, ${ }^{10}$ and parkinsonism. ${ }^{42}$ Second, NIr is equally effective when applied either before or after toxic insult; pre- or posttreatment of NIr, either in vitro ${ }^{55}$ or in vivo, ${ }^{40}$ mitigates MPTP-induced cell damage. Third, our measurements using high-performance liquid chromatography and liquid chromatography/ mass spectrometry indicate that NIr does not directly degrade MPTP (unpublished observations). Finally, NIr has been shown to have a direct influence on intrinsic cellular activity, $7,15,16,47$ as well as being directly effective in reducing cell death induced by apoptosis. ${ }^{44}$ Taken together, these findings all strongly support the idea that NIr provides genuine cellular interaction and neuroprotection.

\section{Apomorphine-Induced Rotational Behavior}

Rats were given an intraperitoneal injection of apomorphine (Apokinon, dopaminergic agonist; $0.5 \mathrm{mg} / \mathrm{kg}$; Aguettant), and they were monitored for any rotational behavior postsurgery. ${ }^{14,51}$ A measure of the extent of the 6-OHDA lesion is the number of contralateral rotations a rat may make soon after each injection. The number of rotations of each rat was counted for 10 minutes postinjec$\operatorname{tion}^{14,51}$ the day before surgery (Day -1 ) and Day 7, Day 14, and Day 21 postsurgery.

\section{Immunohistochemical Analysis}

At the end of the experimental period, rats were anesthetized with an intraperitoneal injection of sodium pentobarbital $(40 \mathrm{mg} / \mathrm{kg})$. They were then perfused transcardially with phosphate-buffered saline (PBS) followed by $4 \%$ buffered paraformaldehyde. The brains were removed and postfixed overnight in the same solution. Next, brains were placed in PBS with the addition of $30 \%$ sucrose until the block sank. The forebrain was then sectioned coronally and serially (at $50 \mu \mathrm{m}$ ) using a freezing microtome. All sections were collected in PBS, then immersed in a solution of PBS and 10\% normal mouse serum (M5905 Sigma), and then in PBS and 1\% Triton (X100 Sigma) each for approximately 1 hour at room temperature. Sections were then incubated in either anti-tyrosine hydroxylase (TH; 1:500; T8700 Sigma), anti-glial fibrillary acidic protein (GFAP; 1:500; Z033429-2 Dako), or anti-ionized calcium binding adaptor molecule 1 (IBA1; 1:500; 019-19741 Wako) for 48 hours (at $4^{\circ} \mathrm{C}$ ), followed by biotinylated anti-rabbit IgG for 4 hours and then Extravidinperoxidase complex for 2 hours (both at room temperature; 1:20; EXTRA3-1KT Sigma). To visualize the bound antibody, sections were reacted in a 3,3'- diaminobenzidine tetrahydrochloride solution (D3939 Sigma). Sections were mounted onto gelatinized slides, air-dried overnight, dehydrated in ascending alcohols, cleared in Histo-Clear (Sigma), and coverslipped using DPX mounting medium (Sigma). As a rule, forebrain sections (including $\mathrm{CPu}$ ) were immunostained for $\mathrm{TH}$, while midbrain (including implant site) sections were immunostained for TH, GFAP, or IBA1 or were Nissl-stained with cresyl violet. For controls, sections were processed as described above, except that no primary antibody was used. These control sections were immunonegative.

\section{Statistical Analysis}

The number of $\mathrm{TH}+$ cells within the $\mathrm{SNc}$ (main body of the nucleus, i.e., ventral tier) $)^{13,46}$ was estimated using the optical fractionator method (StereoInvestigator, MBF Science), as outlined previously. ${ }^{12,28,32,33,40,42,45,52,53}$ Briefly, systematic random sampling of sites-with an unbiased counting frame-within defined boundaries of the SNc was undertaken. All cells that came into focus within the frame were counted and at least 7 sites were sampled per section in the SNc. Cell counts were made on the RHS of the brain, the side injected with either 6-OHDA or saline, because most nigral pathways are ipsilateral. ${ }^{38}$ For group comparisons of cell number, a 1-way ANOVA test was performed (overall comparison of means between groups; $\mathrm{F}$ and $\mathrm{p}$ values), in conjunction with a post hoc multiple comparison test (comparison of means between pairs of groups; $p$ value) that was incorporated within the software (GraphPad Prism v6).

\section{Results}

In the section that follows, the results relating to the apomorphine-induced rotational behavior, the 6-OHDA injection and optical fiber implant sites, together with the number and morphology of SNc cells, will be considered separately.

\section{Apomorphine-Induced Rotational Behavior}

No major adverse effects were observed in the rats after surgery for either the implantation of the optical fiber devices or the 6-OHDA lesion. All rats resumed normal activity (eating and grooming) within a few hours after surgery and were never in any visible discomfort during the entire survival period. ${ }^{13,18,31,32}$ There was no obvious impact of NIr on the normal activity of the rats; the activity of NIr-treated rats was not any different from that of untreated rats. In the NIr-treated rats, the NIr filled the cranial cavity, being evident through the biological cement surrounding the LED device, through the skin and hair over the cranium, the auricles, and through the orbit and eyes (Fig. 2D and E). Hence, as with our previous results in mice, ${ }^{32}$ the intracranially applied NIr was well tolerated by the rats, with no clear deleterious signs.

Figure 3 shows the apomorphine-induced rotational behavior in rats of the different experimental groups. On the day before surgery (Day -1), all the rats in the different groups displayed no rotational behavior after apomorphine injection. In some cases, there was hyperkinetic movement after apomorphine injection, but it soon settled. In the saline group, there was never any apomorphine-induced rotational behavior throughout the 3-week period. In the 6-OHDA group, by contrast, a steady increase in the number of apomorphine-induced rotations, from Day 7 to Day 21, was evident. This indicated the development of a clear functional lesion. In all 6-OHDA-NIr groups, evidence was present of rotational behavior also, but in the 6-OHDA-NIrP and 6-OHDA-NIrC+ groups, it was considerably less than in the 6-OHDA group. This was clearly the case at Day 21, when the differences between the 6-OHDA group and both the 6-OHDA-NIrP $(\mathrm{p}<0.05)$ and, in particular, the $6-\mathrm{OHDA}-\mathrm{NIrC}+(\mathrm{p}<0.001)$ groups 
were significant. The fewer rotations in these groups suggested that NIr had reduced the functional lesion generated by 6-OHDA. Similar patterns were not evident for the 6-OHDA-NIrC group, however, that received NIr at a weaker power (Table 1). In this NIr-treated group, the development and number of apomorphine-induced rotations from Day 7 to Day 21 largely followed that apparent in the 6-OHDA group (Fig. 3). Overall, the differences between the 6-OHDA and 6-OHDA-NIr groups did not reach significance at Day 7 (ANOVA: $F=1.4, p=0.3$ ) and Day 14 (ANOVA: $\mathrm{F}=2.0, \mathrm{p}=1.2$ ), but did so at Day 21 (ANOVA: $\mathrm{F}=4.1, \mathrm{p}<0.01)$.

\section{6-OHDA CPu Injection Sites}

Figure 4 shows $\mathrm{TH}$-immunostained sections of the $\mathrm{CPu}$ on the injected RHS of the saline (Fig. 4A), 6-OHDA (Fig. 4B), and 6-OHDA-NIr (Fig. 4C; 6-OHDA-NIrP) groups. In the saline group, injection sites were characterized by a central core of gliosis, indicating the pipette tract; in the regions immediately surrounding the tract, there was no clear loss of $\mathrm{TH}$ immunoreactivity (Fig. 4A). In the 6-OHDA and 6-OHDA-NIr groups (all 6-OHDA-NIr groups showed similar patterns), a comparable arrangement of gliosis indicating pipette tract was also seen, but in these cases, the tract was surrounded by a region devoid of dense $\mathrm{TH}+$ terminations; in this region, there were only a few $\mathrm{TH}+$ axons and terminals seen (Fig. 4B and C). This largely barren, $\mathrm{TH}-$ region was due to 6-OHDA toxicity and was similar in the 6-OHDA and 6-OHDA-NIr groups (Fig. 4B and C).

\section{Optical Fiber Midbrain Implant Sites}

Figure 5 shows schematic diagrams (Fig. 5A) and a photomicrograph montage (Fig. 5B) of an optical fiber tract through the midbrain. This particular fiber trace was from a rat in the 6-OHDA-NIrP group, but it is typical of the traces we saw in other groups. The implant site in each rat was close to the midline in the midbrain, traversing the red nucleus and lying close to or within the VTA. The distinct square shape of the optical fiber tip was often identifiable (Fig. 5B).

Figure 6 shows photomicrographs comparing Nisslstained (Fig. 6A and B), GFAP-immunostained (Fig. 6C and D), and IBA1-immunostained (Fig. 6E and F) cells in regions immediately adjacent to the implant site in saline-sham (Fig. 6A, C, and E) and NIr-treated (Fig. 6B, D, and $F$ ) rats. In general, no major differences were found in the organization and morphology of neurons and glial cells near the implant sites in the different rats. Each of the optical fiber tracts and implant sites generated localized gliosis and some neuronal degeneration, but these patterns were the same in all of the rats, regardless of whether there was NIr treatment or not. The only cellular damage evident appeared mechanical, being caused after tissue displacement by the optical fiber itself. In addition, we never saw localized zones of necrosis near the tip of the optical fiber, where the NIr was most intense (Fig. 5B). Finally, there appeared to be no impact of NIr on the cytoarchitecture in regions near the implant site, most notably, the SNc (Fig. 5B).

\section{Number and Morphology of SNc Cells}

In this study, we used $\mathrm{TH}$ immunocytochemistry to assess patterns of neuroprotection in the SNc. As with many previous studies, we interpreted $\mathrm{TH}+$ cell number after experimental manipulation as an index of cell survival. $^{12,28,32,33,40,42,45,52,53}$ If cells lose TH expression, then they are likely to undergo death subsequently., ${ }^{4,22,25}$ Notwithstanding a small number of cells that may have transient loss of TH expression, a key outcome measure for our study was whether NIr treatment mitigated the loss of $\mathrm{TH}+$ cells caused by the 6-OHDA. . $^{2,28,32,33,40,42,45,52,53}$

Figure 7 shows a graph of the estimated total number of $\mathrm{TH}+$ cells in the SNc of the 5 experimental groups. A

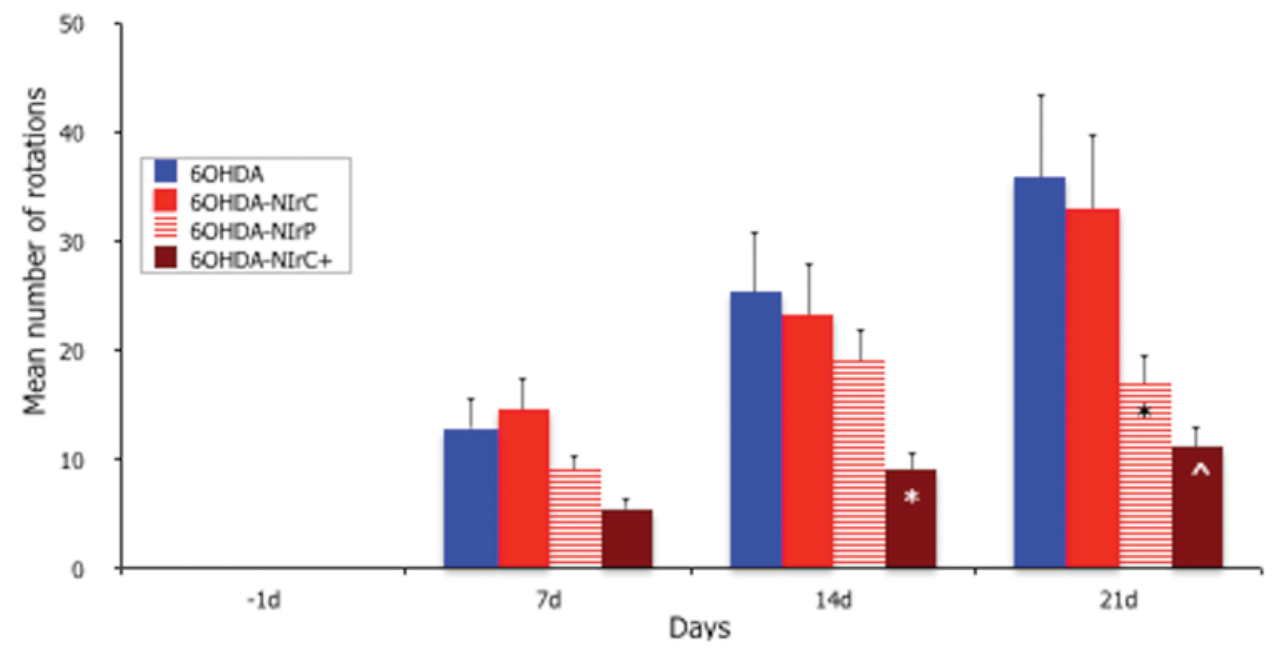

FIG. 3. Graph showing the mean number of apomorphine-induced turns of rats (in 10 mins) in the 6-OHDA, 6-OHDA-NIrP, 6-OHDA-NIrC, and 6-OHDA-NIrC+ groups at 4 time points, 1 day before surgery (Day -1) and Day 7, Day 14, and Day 21 postsurgery. The saline group had no rotational behavior throughout the experimental period (not shown). Symbols adjacent to particular markers represent the level of significant difference from the 6-OHDA group on that day of testing; ${ }^{\wedge} p<0.001,{ }^{*} p<0.05$. All columns show the mean \pm standard error in each group. Figure is available in color online only. 

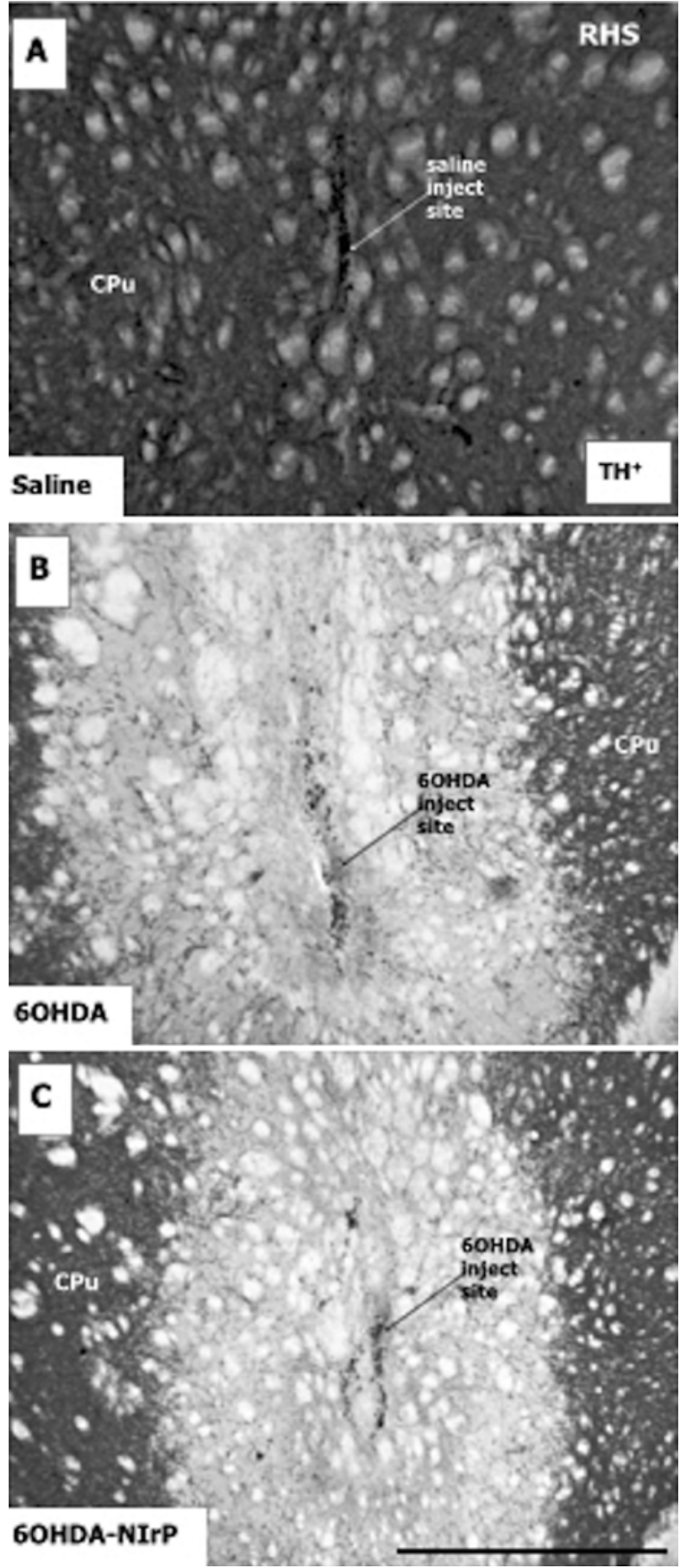

FIG. 4. Photomicrographs of saline and 6-OHDA injection sites on the RHS CPu in the saline (A), 6-OHDA (B), and 6-OHDA-NIrP (C) groups (labeling patterns were similar in the other 6-OHDA-NIr groups, hence not shown). Sections were immunostained for $T H$, and the saline $(A)$ or 6-OHDA ( $\mathrm{B}$ and $\mathrm{C}$ ) injection sites are indicated by arrows. In each 6-OHDA injection site, there was a central core of gliosis indicating the pipette tract, surrounded by a striatal region devoid of rich TH immunostaining ( $\mathrm{B}$ and $\mathrm{C})$. This non-TH immunostained region was as a result of the 6-OHDA toxicity to the dopaminergic terminals. The injection sites in the 6-OHDA and all 6-OHDA-NIr groups were very similar. In each saline injection site, there was a central core of gliosis and pipette tract, but no surrounding region of non-TH immunostaining (A). All figures are of coronal sections; dorsal to top and lateral to right for RHS images and lateral to left for LHS image. Bar $=1 \mathrm{~mm}$. clear reduction occurred in the number of $\mathrm{TH}+$ cells in the 6-OHDA group compared with the saline group (approximately $25 \% ; \mathrm{p}<0.05)$. In the 6 -OHDA-NIrP group, $\mathrm{TH}+$ cell number was considerably higher than that in the 6 -OHDA group (approximately 25\%; $\mathrm{p}<0.001$ ), equivalent to that in the saline group, i.e., pulse delivery of NIr appeared to mitigate the cell loss caused by 6-OHDA toxicity. A comparable mitigation was not, however, evident in the other 6-OHDA-NIr groups; the number of TH+ cells in the 6-OHDA-NIrC and 6-OHDA-NIrC+ groups was similar to that in the 6-OHDA group ( $p>0.05$; Fig. 7). Thus, NIr treatment mitigated $\mathrm{TH}+$ cell loss after 6-OHDA lesion, but only under certain conditions. It was far more effective after pulse delivery (6-OHDA-NIrP group) than after continuous delivery either at the same (6-OHDA$\mathrm{NIrC}+$ group) or weaker (6-OHDA-NIrC group) NIr power. Overall, when comparing all the groups together, the overall differences in the number of $\mathrm{TH}+$ cells were significant (ANOVA: $\mathrm{F}=3.2, \mathrm{p}=0.02$ ).

Figure 8 shows photomicrographs of $\mathrm{TH}+$ cells in the SNc of the saline (Fig. 8A), 6-OHDA (Fig. 8B; similar patterns were seen in the 6-OHDA-NIrC and 6-OHDA$\mathrm{NIrC}+$ groups), and 6-OHDA-NIrP (Fig. 8C) groups. Although the morphology of TH+ cells was similar in all the groups, the 6-OHDA (and 6-OHDA-NIrC and 6-OHDA$\mathrm{NIrC}+$ ) group had fewer cells and more degenerating axonal profiles (Fig. 8B arrow) than the saline and 6-OHDANIrP groups had.

\section{Discussion}

We have shown that intracranially delivered NIr mitigated behavioral deterioration and the loss of midbrain dopaminergic cells in 6-OHDA-lesioned rats. Quite strikingly, NIr-induced mitigation of dopaminergic cell loss did not account for all the behavioral improvements; the NIr applications that reduced apomorphine-induced rotations did not all necessarily generate a greater number of surviving dopaminergic cells. This discrepancy will be the major focus of the discussion below. First, we will consider the feasibility of the midbrain as a target for optical fiber implants.

\section{Feasibility of a Midbrain Target Site for Intracranial Delivery of NIr}

One of our major aims was to explore the feasibility of the midbrain as an implant site. Our previous study in mice targeted the lateral ventricle, ${ }^{32}$ but for our planned primate endeavors, we hope to target a midline region of the midbrain. This region was chosen because it is near the $\mathrm{SNc}$, and it provides equal doses of NIr to the nucleus of the left and right side. Our results show that, after 23 days of pulse or continuous NIr treatment of the midbrain, there were no adverse effects on the well-being of the rats that, once they recovered from surgery, were never observed to be in any discomfort. Furthermore, our immunohistochemical and histological results revealed little evidence of tissue necrosis or gliosis caused by the intracranially delivered NIr. In each case, the tissue damage observed appeared mechanical, being caused by the optical fiber itself. Taken together, these data indicated that the midbrain is indeed 


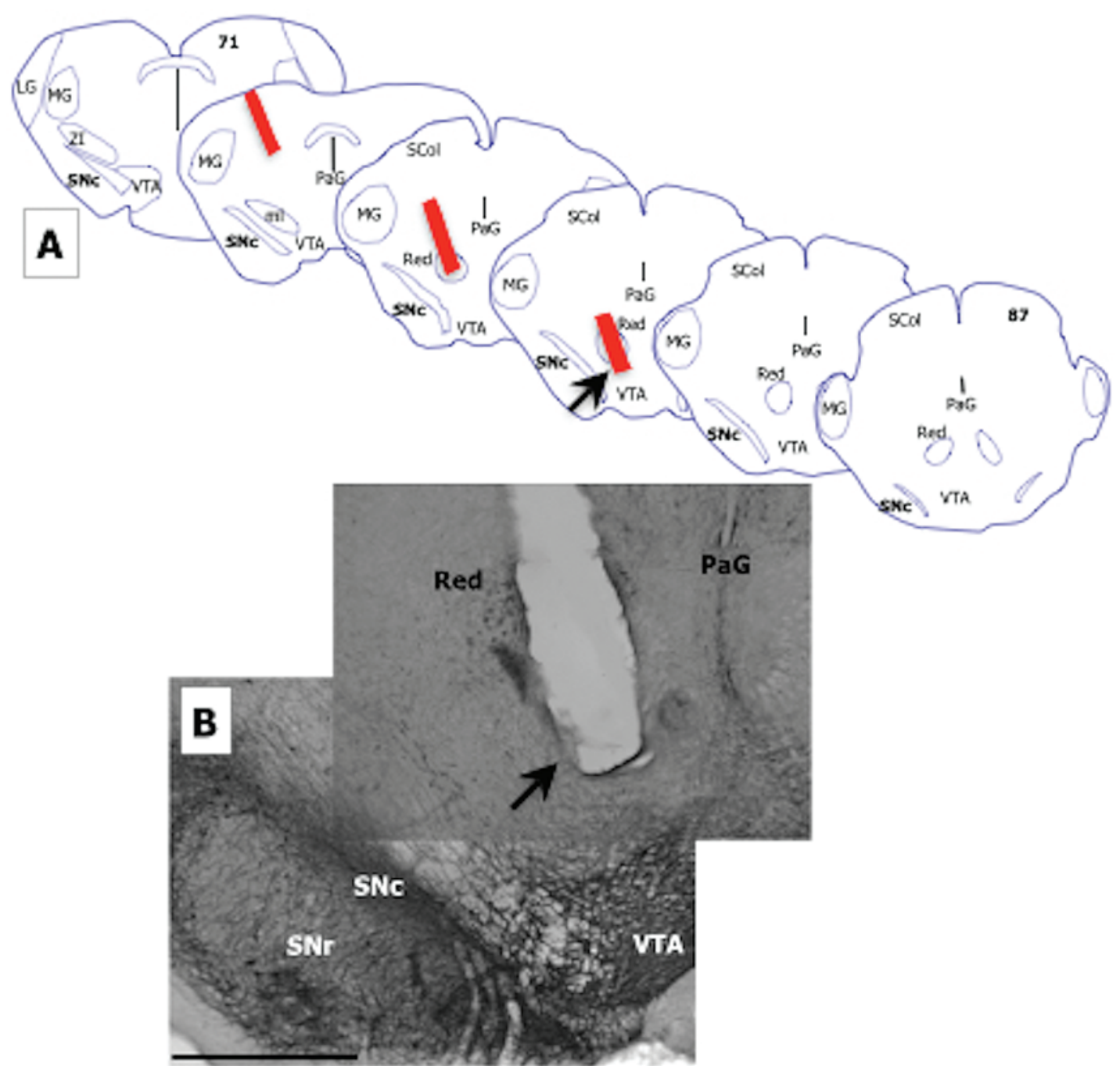

FIG. 5. A: Schematic diagrams of coronal sections, across the rostrocaudal axis (from left to right; plates $71-87$ of rat atlas), ${ }^{39}$ from where our stereological analysis was undertaken. The red rectangles indicate the typical extent and location of the majority of our implant sites within the midbrain. This case was from the 6-OHDA-NIrP group; implant sites from the other groups were similar. B: Photomicrograph montage of a typical implant site from $\mathrm{TH}+$ immunostained sections. This case was from the 6-OHDA-NIrP group and is the same animal as depicted in $(A)$. The arrows in both $A$ and $B$ indicate the approximate region where the photomicrographs in Fig. 6 were taken. Sections are of coronal sections; in B, lateral to left, dorsal to top. MG = medial geniculate nucleus; $\mathrm{LG}=$ lateral geniculate nucleus; $\mathrm{PaG}=$ periaqueductal gray matter; $\mathrm{SCol}=$ superior colliculus. $\mathrm{Bar}=1 \mathrm{~mm}$. Figure is available in color online only.

a feasible implant site, and when applied at the therapeutic doses we used (i.e., $0.16 \mathrm{~mW}$ power), the intracranially delivered NIr generated no adverse effect on brain tissue or well-being of the rats. Previous studies have reported that adverse effects may be detected if power output is in a range well over what is needed for neuroprotection, perhaps 10 times more..$^{20,25}$

\section{Impact of NIr Treatment on Behavior and Cell Survival in 6-OHDA-Lesioned Rats}

Many previous studies have used apomorphine-induced turning behavior as a means of assessing the extent of unilateral 6-OHDA lesions in either the striatum or medial forebrain bundle; the larger the lesion, the more turning behavior is evident. ${ }^{5,6,13,14,18,31,41,50,51}$ In this context, several studies have used this behavioral test to measure the de- gree of neuroprotection, whether a given neuroprotective agent reduces the number of apomorphine-induced turns in 6-OHDA-lesioned rats.,19,26,30 In this study, we tested various NIr applications in 6-OHDA-lesioned rats, using 2 modes of NIr delivery (pulse and continuous), powers (333 nW and $0.16 \mathrm{~mW}$ ), and total doses (634 mJ or 304 $\mathrm{J})$. We found that the stronger NIr power, regardless of delivery mode or total dose, generated a clear reduction in apomorphine-induced rotations in 6-OHDA-lesioned rats (6-OHDA-NIrP and 6-OHDA-NIrC+ groups); by contrast, no reduction was evident with the weaker power (6-OHDA-NIrC group). It is likely that the NIr signal issued by the weaker power did not penetrate the short distance to the $\mathrm{SNc}$ and elicit a functional response, while the stronger power did.

The most reasonable explanation for these behavioral 


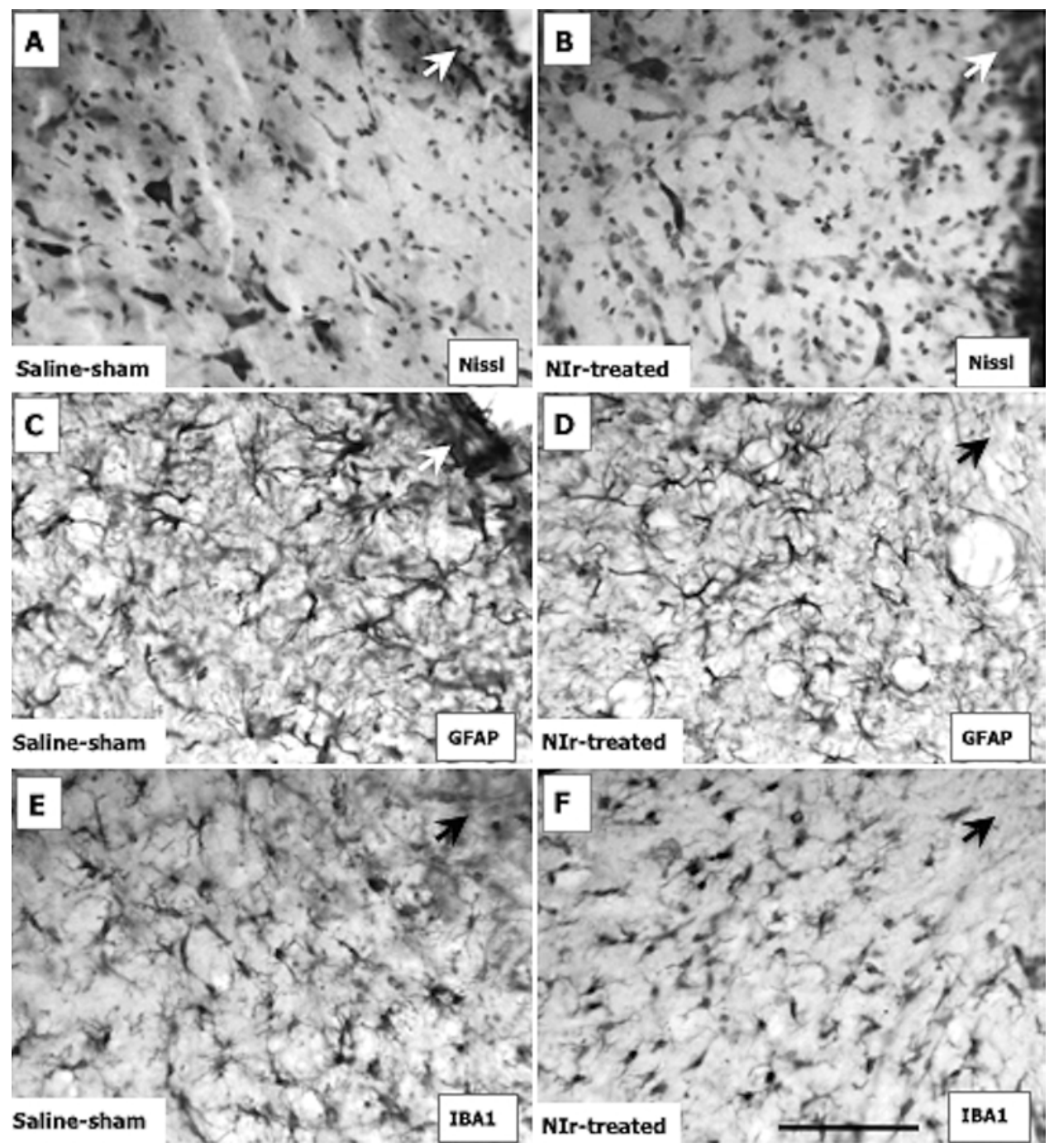

FIG. 6. Nissl-stained (A and B), GFAP+ (C and D), and IBA+ (E and F) cells in regions adjacent to optical fiber implant sites in the midbrain of rats in the saline $(A, C$, and $E$ ) and Nlr-treated $(B, D$, and $F)$ cases. The region from which these photomicrographs were taken is indicated by arrows in Fig 5 . The white arrows indicate the edge of the implant site. Each optical fiber implant site was associated with gliosis; there were no obvious differences between the saline-sham (non-NIr) and the NIr-treated cases. The gliosis around the implant site appeared due to mechanical damage caused by the optical fiber itself, with no clear signs of NIr toxicity; gliosis was evident along the length of the optical fiber, well away from the fiber tip, where the NIr was most intense. The NIr-treated case shown here was from a rat in the 6-OHDA-NIrC+ group, representative of all other 6-OHDA-NIr groups. All figures are of coronal sections, dorsal to top and medial to left. Bar $=100 \mu \mathrm{m}$.

improvements at the stronger NIr power would be that they reflected a neuroprotection of dopaminergic cells, manifesting in a preservation of functional activity and dopaminergic transmission through the striatum. ${ }^{27}$ This neuroprotection would have addressed the asymmetry of striatal transmission after a 6-OHDA lesion and contributed to the reduction in turning behavior.,17,26,30 Following this thinking, neuroprotection would have been expected in the groups that had improvements in behavior, namely the 6-OHDA-NIrP and 6-OHDA-NIrC+ groups, but not in the 6-OHDA-NIrC group, the group that had no behavioral improvement. Somewhat surprisingly, however, this was not entirely the case. Although neuroprotection was evident in the 6-OHDA-NIrP group, and not in the 6-OHDA-NIrC group, it was not evident in the 6-OHDA-NIrC+ group, the group that displayed the clearest improvement in behavior (Fig. 3). Hence, NIr-induced neuroprotection could not account for all the observed behavioral improvements; there may have been other "symptomatic" elements contributing to the improvements in these cases, not just an increase in cell survival. In essence, these results indicated that patterns of cell survival might not necessarily be the most important element of all behavioral changes. The sources of these symptomatic elements are not known, but there are several possibilities. NIr treatment may have stimulated the activity of the dopaminergic cells, in an attempt to maintain dopaminergic transmission through the striatum and to mask the cellular deficit. This effect may have been heightened in the remaining cells in the 6-OHDA-NIrC+ group to compensate for the smaller size of the 


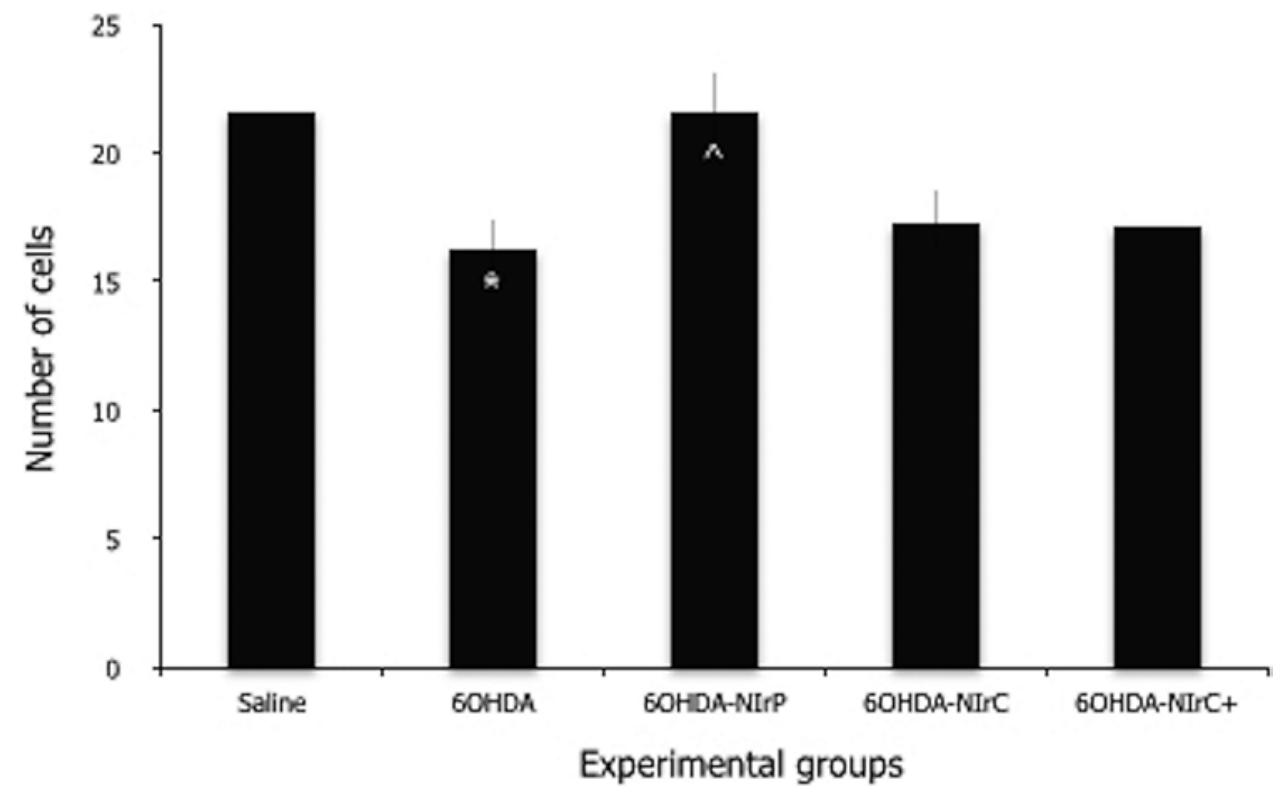

FIG. 7. Graphs showing the number of $\mathrm{TH}+$ cells in each of the experimental groups. Numbers represent counts from the RHS 6-OHDA-lesioned side. The symbols within the columns of the 6-OHDA group represent levels of significant difference from the saline group, while symbols within the columns of any of the 6-OHDA-NIr groups represent significant differences in the 6-OHDA group. ${ }^{\wedge} p<0.001,{ }^{*} p<0.05$. All columns show the mean \pm standard error in each group.

surviving dopaminergic cell population. Alternatively, NIr treatment may have stimulated the activity of nondopaminergic cell groups in the brain, such as those involved in generating movement (e.g., motor cortex, pedunculopontine tegmental nucleus). ${ }^{38}$ These structures are certainly close enough to the rat midbrain to be influenced by the NIr signal issued from the optical fiber device; previous studies have reported that the NIr signal can be measured approximately $30 \mathrm{~mm}$ from the source (see above), and the rat motor cortex $(5-10 \mathrm{~mm})$ and pedunculopontine tegmental nucleus (approximately $1 \mathrm{~mm}$ ) are well within that distance from the midbrain. ${ }^{39} \mathrm{~A}$ clear challenge for future studies would be to reveal the source of these symptomatic elements, whether dopaminergic or nondopaminergic, and if they are sustainable, in the longer-term, without any underlying neuroprotection (i.e., in the 6-OHDA-NIrC+ group).

Previous studies have reported that NIr stimulates mitochondria by increasing ATP content and electron transfer in the respiratory chain through activation of photoacceptors (e.g., cytochrome oxidase), together with modulating reactive oxygen species and the induction of various transcription factors. $711,15,16,19,29,47,55$ In this study, NIr may have induced such factors to 1) protect cells against toxic insult, leading to a greater cell survival, or 2) stimulate the functional activity of cells, leading subsequently to improvements in behavior, or both 1 and 2 . We showed that the pulse mode was more effective in generating both neuroprotection and improved behavior (6-OHDA-NIrP group), while the continuous mode was effective in improving behavior only (6-OHDA-NIrC+ group). The reason why the continuous mode did not induce neuroprotection is not known, but we suggest that it was related to the high total dose of NIr delivered in this group (304 J); this higher dose may have been within the range for inducing an increase in functional activity but not for inducing neuroprotection, while the lower dose $(634 \mathrm{~mJ})$ may have been within the range to induce both beneficial effects. NIr has been shown to be most effective in intermediate doses, but not at very low or extremely high doses, the so-called "hormetic effect." ${ }^{7,19,47}$ This effect may help explain some of our results here. There may be different hormetic dose-response curves for neuroprotection and functional activity; the curve-inducing cell repair mechanisms and neuroprotection may drop off more quickly with increasing NIr dosage than the curve for activating functional activity, hence contributing to the differences in beneficial effects. ${ }^{48}$ This issue of different biological effects by the same agent at different doses is worthy of further study.

In summary, if given at sufficient power to penetrate brain tissue and reach the $\mathrm{SNc}(0.16 \mathrm{~mW})$, a pulse delivery of NIr that did not result in a very high total dose (e.g., $634 \mathrm{~mJ})$, generated both neuroprotection and behavioral (functional) improvements. If the NIr power delivered was very weak (e.g., $333 \mathrm{nW}$ ) or if it manifested in too high a dose (e.g., $304 \mathrm{~J}$ ), then not all the beneficial effects (neuroprotection and behavior) were evident.

\section{Conclusions}

We have shown that, as in the MPTP-treated mouse model, ${ }^{32}$ intracranially delivered NIr was well tolerated by the animals, did not cause tissue toxicity, improved behavior, and was neuroprotective in the 6-OHDA-lesioned rat model. These positive findings in a second animal model of Parkinson's disease provide further encouragement for a positive outcome in humans. Our results show that protection of dopaminergic cells did not account for all the observed behavioral improvements, and that different applications of NIr generated different beneficial out- 

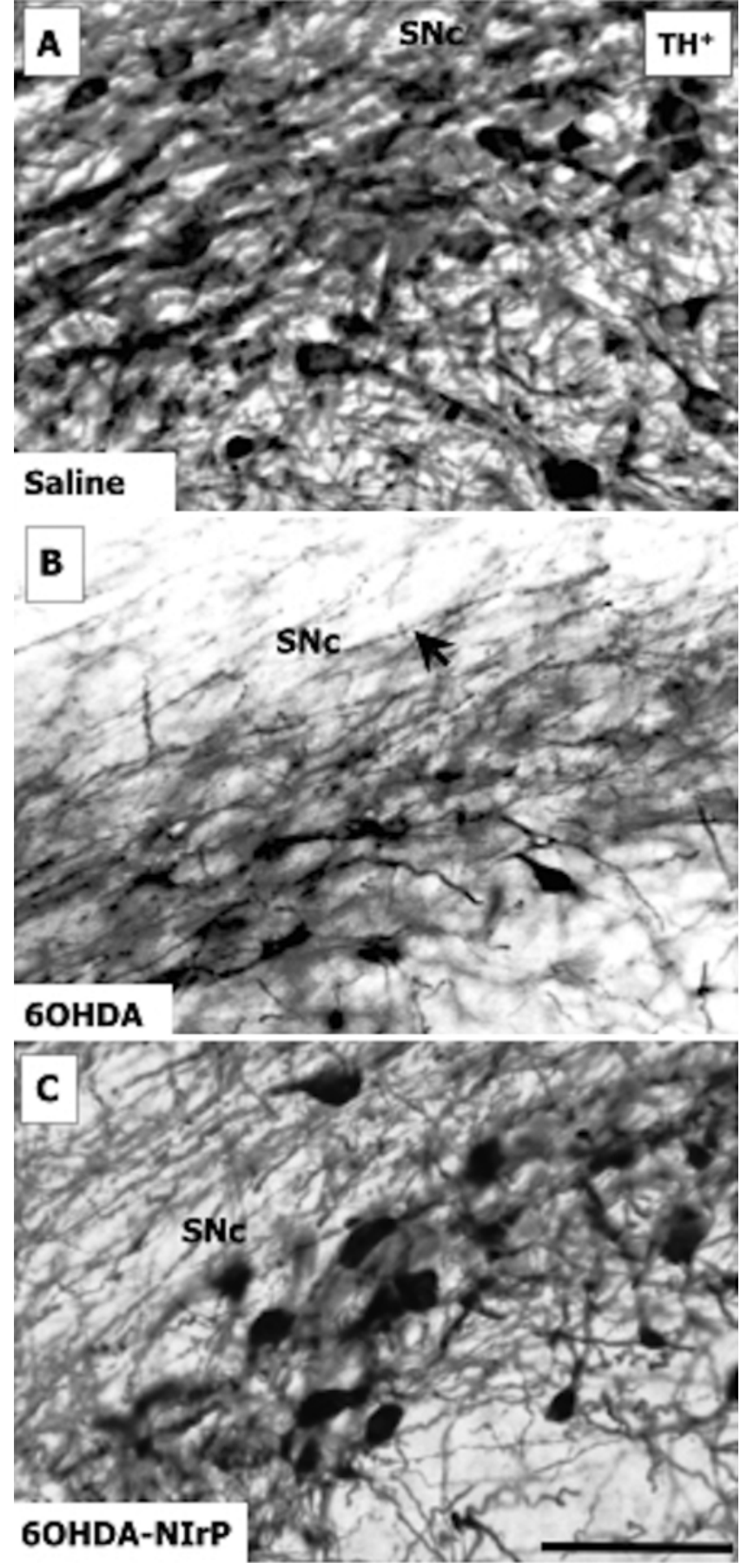

FIG. 8. Photomicrographs of TH+ cells in the saline (A), 6-OHDA (B), and 6-OHDA-NIrP (C) groups on the RHS (6-OHDA- or saline-injected sides). Labeling patterns on the LHS for the 6-OHDA and all 6-OHDANIr groups were similar to those in the saline group, while patterns on the RHS in the 6-OHDA group were similar to those observed in the 6-OHDA-NIrC+ and 6-OHDA-NIrC groups (not shown). Arrow in (B) indicates degenerating axons. All figures are of coronal sections; dorsal to top and lateral to right $(B, D$, and $F)$ and to left $(A, C$, and $E)$. Bar = $100 \mu \mathrm{m}$.

comes. A careful titration of NIr application would hence be essential when considering use in humans, establishing a power, mode of delivery, and total dose that generates improvements both in behavior and neuroprotection.
These early findings provide much encouragement for the future.

\section{Acknowledgments}

We are forever grateful to the Michael J. Fox Foundation, Fondation Philanthropique Edmond J. Safra, France Parkinson and the French National Research Agency (ANR Carnot Institute), Tenix Corp., and the Salteri family for funding this work. D.M.J. is an Early Career Fellow of the NHMRC (Australia). We thank Sharon Spana, Guillaume Barboux, Clément Perrin, Cyril Zenga, Diane Agay, and Mylène D'Orchymont for excellent technical assistance.

\section{References}

1. Baluchnejadmojarad T, Roghani M, Nadoushan MRJ, Bagheri M: Neuroprotective effect of genistein in 6-hydroxydopamine hemi-parkinsonian rat model. Phytother Res 23:132-135, 2009

2. Bergman H, Deuschl G: Pathophysiology of Parkinson's disease: from clinical neurology to basic neuroscience and back. Mov Disord 17 (Suppl 3):S28-S40, 2002

3. Bezard E, Yue Z, Kirik D, Spillantini MG: Animal models of Parkinson's disease: limits and relevance to neuroprotection studies. Mov Disord 28:61-70, 2013

4. Björklund A, Rosenblad C, Winkler C, Kirik D: Studies on neuroprotective and regenerative effects of GDNF in a partial lesion model of Parkinson's disease. Neurobiol Dis 4:186200, 1997

5. Blesa J, Phani S, Jackson-Lewis V, Przedborski S: Classic and new animal models of Parkinson's disease. J Biomed Biotechnol 2012:845618, 2012

6. Bové J, Perier C: Neurotoxin-based models of Parkinson's disease. Neuroscience 211:51-76, 2012

7. Chung H, Dai T, Sharma SK, Huang YY, Carroll JD, Hamblin MR: The nuts and bolts of low-level laser (light) therapy. Ann Biomed Eng 40:516-533, 2012

8. DeSmet K, Buchmann E, Henry M, Wong-Riley M, Eells J, VerHoeve J, et al: Near-infrared light as a possible treatment option for Parkinson's disease and laser eye injury. Proc SPIE 7165:716503, 2009

9. DeSmet KD, Paz DA, Corry JJ, Eells JT, Wong-Riley MTT, Henry MM, et al: Clinical and experimental applications of NIR-LED photobiomodulation. Photomed Laser Surg 24:121-128, 2006

10. De Taboada L, Yu J, El-Amouri S, Gattoni-Celli S, Richieri S, McCarthy T, et al: Transcranial laser therapy attenuates amyloid- $\beta$ peptide neuropathology in amyloid- $\beta$ protein precursor transgenic mice. J Alzheimers Dis 23:521-535, 2011

11. Eells JT, Wong-Riley MTT, VerHoeve J, Henry M, Buchman EV, Kane MP, et al: Mitochondrial signal transduction in accelerated wound and retinal healing by near-infrared light therapy. Mitochondrion 4:559-567, 2004

12. El Massri N, Johnstone DM, Peoples CL, Moro C, Reinhart F, Torres N, et al: The effect of different doses of near infrared light on dopaminergic cell survival and gliosis in MPTPtreated mice. Int $\mathbf{J}$ Neurosci [epub ahead of print], 2015

13. Fitzpatrick E, Ashkan K, Wallace BA, Benabid A-L, Mitrofanis J: Differential survival patterns among midbrain dopaminergic cells of MPTP-treated monkeys and 6-OHDAlesioned rats. Anat Embryol (Berl) 210:101-123, 2005

14. Fujita M, Nishino H, Kumazaki M, Shimada S, Tohyama M, Nishimura T: Expression of dopamine transporter mRNA and its binding site in fetal nigral cells transplanted into the striatum of 6-OHDA lesioned rat. Brain Res Mol Brain Res 39:127-136, 1996

15. Gonzalez-Lima F, Barrett DW: Augmentation of cognitive brain functions with transcranial lasers. Front Syst Neurosci 8:36, 2014 
16. Hamblin MR, Demidova TN: Mechanisms of low level light therapy. Proc SPIE 6140:614001, 2006

17. Han B, Hu J, Shen J, Gao Y, Lu Y, Wang T: Neuroprotective effect of hydroxysafflor yellow A on 6-hydroxydopamineinduced Parkinson's disease in rats. Eur J Pharmacol 714:83-88, 2013

18. Heise CE, Mitrofanis $\mathrm{J}$ : Reduction in parvalbumin expression in the zona incerta after 6-OHDA lesion in rats. J Neurocytol 34:421-434, 2005

19. Huang YY, Chen ACH, Carroll JD, Hamblin MR: Biphasic dose response in low level light therapy. Dose Response 7:358-383, 2009

20. Ilic S, Leichliter S, Streeter J, Oron A, DeTaboada L, Oron U: Effects of power densities, continuous and pulse frequencies, and number of sessions of low-level laser therapy on intact rat brain. Photomed Laser Surg 24:458-466, 2006

21. Ivandic BT, Ivandic T: Low-level laser therapy improves vision in patients with age-related macular degeneration. Photomed Laser Surg 26:241-245, 2008

22. Jackson-Lewis V, Jakowec M, Burke RE, Przedborski S: Time course and morphology of dopaminergic neuronal death caused by the neurotoxin 1-methyl-4-phenyl-1,2,3,6tetrahydropyridine. Neurodegeneration 4:257-269, 1995

23. Jankovic J: Parkinson's disease: clinical features and diagnosis. J Neurol Neurosurg Psychiatry 79:368-376, 2008

24. Jankovic J, Poewe W: Therapies in Parkinson's disease. Curr Opin Neurol 25:433-447, 2012

25. Javoy-Agid F, Hirsch EC, Dumas S, Duyckaerts C, Mallet J, Agid Y: Decreased tyrosine hydroxylase messenger RNA in the surviving dopamine neurons of the substantia nigra in Parkinson's disease: an in situ hybridization study. Neuroscience 38:245-253, 1990

26. Joghataie MT, Roghani M, Negahdar F, Hashemi L: Protective effect of caffeine against neurodegeneration in a model of Parkinson's disease in rat: behavioral and histochemical evidence. Parkinsonism Relat Disord 10:465-468, 2004

27. Johnstone D, Coleman K, Moro C, Torres N, Eells J, Baker GE, et al: The potential of light therapy in Parkinson's disease. ChronoPhysiology Therapy 4:1-14, 2014

28. Johnstone DM, el Massri N, Moro C, Spana S, Wang XS, Torres N, et al: Indirect application of near infrared light induces neuroprotection in a mouse model of parkinsonism-an abscopal neuroprotective effect. Neuroscience 274:93-101, 2014

29. Liang HL, Whelan HT, Eells JT, Wong-Riley MTT: Nearinfrared light via light-emitting diode treatment is therapeutic against rotenone- and 1-methyl-4-phenylpyridinium ioninduced neurotoxicity. Neuroscience 153:963-974, 2008

30. Liu X, Shao R, Li M, Yang G: Edaravone protects neurons in the rat substantia nigra against 6-hydroxydopamine-induced oxidative stress damage. Cell Biochem Biophys 70:12471254,2014

31. Luquin N, Mitrofanis J: Does the cerebral cortex exacerbate dopaminergic cell death in the substantia nigra of 6-OHDAlesioned rats? Parkinsonism Relat Disord 14:213-223, 2008

32. Moro C, Massri NE, Torres N, Ratel D, De Jaeger X, Chabrol $\mathrm{C}$, et al: Photobiomodulation inside the brain: a novel method of applying near-infrared light intracranially and its impact on dopaminergic cell survival in MPTP-treated mice. J Neurosurg 120:670-683, 2014

33. Moro C, Torres N, El Massri N, Ratel D, Johnstone DM, Stone J, et al: Photobiomodulation preserves behaviour and midbrain dopaminergic cells from MPTP toxicity: evidence from two mouse strains. BMC Neurosci 14:40, 2013

34. Muili KA, Gopalakrishnan S, Meyer SL, Eells JT, Lyons JA: Amelioration of experimental autoimmune encephalomyelitis in C57BL/6 mice by photobiomodulation induced by $670 \mathrm{~nm}$ light. PLoS One 7:e30655, 2012

35. Olanow CW, Kieburtz K, Schapira AHV: Why have we failed to achieve neuroprotection in Parkinson's disease? Ann Neurol 64 (Suppl 2):S101-S110, 2008

36. Oron A, Oron U, Chen J, Eilam A, Zhang C, Sadeh M, et al: Low-level laser therapy applied transcranially to rats after induction of stroke significantly reduces long-term neurological deficits. Stroke 37:2620-2624, 2006

37. Oron A, Oron U, Streeter J, de Taboada L, Alexandrovich A, Trembovler V, et al: low-level laser therapy applied transcranially to mice following traumatic brain injury significantly reduces long-term neurological deficits. J Neurotrauma 24:651-656, 2007

38. Parent A: Carpenter's Human Neuroanatomy, ed 9. Philadelphia: Williams and Wilkins, 1996

39. Paxinos G, Watson CR: The Rat Brain in Stereotaxic Coordinates, ed 5., Amsterdam: Elsevier, 2005

40. Peoples C, Spana S, Ashkan K, Benabid AL, Stone J, Baker GE, et al: Photobiomodulation enhances nigral dopaminergic cell survival in a chronic MPTP mouse model of Parkinson's disease. Parkinsonism Relat Disord 18:469-476, 2012

41. Piallat B, Benazzouz A, Benabid AL: Subthalamic nucleus lesion in rats prevents dopaminergic nigral neuron degeneration after striatal 6-OHDA injection: behavioural and immunohistochemical studies. Eur J Neurosci 8:1408-1414, 1996

42. Purushothuman S, Nandasena C, Johnstone DM, Stone J, Mitrofanis J: The impact of near-infrared light on dopaminergic cell survival in a transgenic mouse model of parkinsonism. Brain Res 1535:61-70, 2013

43. Quirk BJ, DeSmet KD, Henry M, Buchmann E, Wong-Riley M, Eells JT, et al: Therapeutic effect of near infrared (NIR) light on Parkinson's disease models. Front Biosci (Elite Ed) 4:818-823, 2012

44. Quirk BJ, Torbey M, Buchmann E, Verma S, Whelan HT: Near-infrared photobiomodulation in an animal model of traumatic brain injury: improvements at the behavioral and biochemical levels. Photomed Laser Surg 30:523-529, 2012

45. Reinhart F, Massri NE, Darlot F, Torres N, Johnstone DM, Chabrol C, et al: $810 \mathrm{~nm}$ near-infrared light offers neuroprotection and improves locomotor activity in MPTP-treated mice. Neurosci Res 92:86-90, 2015

46. Rinne JO: Nigral degeneration in Parkinson's disease. Mov Disord 8 (Suppl 1):S31-S35, 1993

47. Rojas J, Gonzalez-Lima F: Low-level light therapy of the eye and brain. Eye Brain 3:49-67, 2011

49. Romeo S, Viaggi C, Di Camillo D, Willis AW, Lozzi L, Rocchi C, et al: Bright light exposure reduces TH-positive dopamine neurons: implications of light pollution in Parkinson's disease epidemiology. Sci Rep 3:1395, 2013

48. Sano M: Cardioprotection by hormetic responses to aldehyde. Circ J 74:1787-1793, 2010

50. Schober A: Classic toxin-induced animal models of Parkinson's disease: 6-OHDA and MPTP. Cell Tissue Res 318:215-224, 2004

51. Schwarting RKW, Huston JP: The unilateral 6-hydroxydopamine lesion model in behavioral brain research. Analysis of functional deficits, recovery and treatments. Prog Neurobiol 50:275-331, 1996

52. Shaw VE, Spana S, Ashkan K, Benabid A-L, Stone J, Baker GE, et al: Neuroprotection of midbrain dopaminergic cells in MPTP-treated mice after near-infrared light treatment. J Comp Neurol 518:25-40, 2010

53. Wallace BA, Ashkan K, Heise CE, Foote KD, Torres N, Mitrofanis J, et al: Survival of midbrain dopaminergic cells after lesion or deep brain stimulation of the subthalamic nucleus in MPTP-treated monkeys. Brain 130:2129-2145, 2007

54. Whelan H, DeSmet K, Buchmann E, Henry M, Wong-Riley M, Eells J, et al: Harnessing the cell's own ability to repair and prevent neurodegenerative disease. SPIE Newsroom 2008:1-3, 2008 
55. Ying R, Liang HL, Whelan HT, Eells JT, Wong-Riley MTT: Pretreatment with near-infrared light via light-emitting diode provides added benefit against rotenone- and MPP+-induced neurotoxicity. Brain Res 1243:167-173, 2008

\section{Disclosures}

Dr. Stone has ownership of CSCM Pty Ltd.

\section{Author Contributions}

Conception and design: Mitrofanis, Reinhart, Chabrol, Benabid,
Moro. Acquisition of data: Mitrofanis, Reinhart, El Massri, Chabrol, Cretallaz, Torres, Darlot, Costecalde, Moro. Analysis and interpretation of data: Mitrofanis, Reinhart, El Massri, Chabrol, Benabid, Moro. Drafting the article: Mitrofanis. Critically revising the article: Mitrofanis, Reinhart, Cretallaz, Johnstone, Stone, Benabid, Moro. Reviewed submitted version of manuscript: all authors. Approved the final version of the manuscript on behalf of all authors: Mitrofanis. Statistical analysis: Mitrofanis. Study supervision: Mitrofanis, Benabid, Moro.

\section{Correspondence}

John Mitrofanis, Department of Anatomy, Anderson-Stuart Bldg. F13, University of Sydney, Sydney, NSW 2006, Australia. email: john.mitrofanis@sydney.edu.au. 